\title{
Stimulus duration and the human heart rate response
}

DAVID B. D. SMITH AND PHYLLIS J. STRAWBRIDGE AMES RESEARCH CENTER, NASA

The adult heart rate response was studied following two durations and two intensities of an auditory stimulus. A I sec tone evoked a predominately acceleratory response and no decrement with repetition. Initially, a $15 \mathrm{sec}$ tone evoked a response characterized by a prolonged deceleration phase. With repetition this changed to an acceleration similar to the 1 sec tone and then showed no decrement with further repetition. Intensity ( 40 and $85 \mathrm{~dB}$ ) did not influence the form of the heart rate response.

Changes in heart rate (HR) evoked by simple stimuli are usually considered to be a component of the orienting response. For auditory stimuli there is little agreement as to the form of these changes. Several studies (Davis et al, 1955; Lang \& Hnatiow, 1962) have reported a diphasic response, an acceleration followed by deceleration. Other studies have reported a response consisting only of HR acceleration (Uno \& Grings, 1965) or only of HR deceleration (Wilson, 1964). Graham \& Clifton (1966) have suggested these differences could be due to the use of different stimulus intensities. Their view is that initial presentations of a weak stimulus should evoke an orienting response of deceleration and more intense stimuli a defense or startle response of acceleration. Studies have also differed in the duration of the stimulus used. Stimuli as brief as $2 \mathrm{sec}$ (Uno \& Grings, 1965) or as long as 5 (Lang \& Hnatiow, 1962) and even $10 \mathrm{sec}$ (McDonald et al, 1964) have been used. The present study investigated the form of the HR response to a series of auditory stimuli as a function of these two variables of intensity and duration. Method

Forty-eight male Ss (mean age 18.7) were assigned alternately to one of two groups. Both groups received (via earphones) a $4000 \mathrm{~Hz}$ tone, one group at $40 \mathrm{~dB}$ and the second at $85 \mathrm{~dB}$. Intensities were determined by a General Radio meter (re .0002 dyne $/ \mathrm{cm}^{2}$ ). Each $S$ took part in two session one week apart. At the first session half of the Ss in each intensity group received tones $1 \mathrm{sec}$ long and the other half tones $15 \mathrm{sec}$ long. At the second session Ss were interchanged between the two duration conditions. All Ss were given 16 tones per session with an interval of $30 \mathrm{sec}$ from onset to onset.

For the experiment, $S$ reclined on a cot and continuous recordings of $\mathrm{HR}$ and respiration were made. A cardiotachometer derived $\mathbf{H R}$ from the ECG and respiration rate was measured from changes in chest diameter. Each $S$ was told that he would receive an occasional tone. To insure his attentiveness, he was asked to count the tones and told to report the total number at the end of the experiment. After 4 min of basal level recording a warning was given to $S$ that the tones would start in $1 \mathrm{~min}$.

HR was measured (to within one beat) from the beat-to-beat record of the cardiotachometer. The measure of prestimulus HR was the mean rate for three beats just prior to the stimulus. The HR response was the difference between this value and the mean for 18 successive beats following onset of the tone. For respiration rate analysis was based on the difference between the mean of the three cycles preceding and the three cycles following stimulus onset. To increase stability the data were grouped into trial blocks, each block the mean of two successive stimuli. Statistical analysis was by analysis of variance for repeated measures.

\section{Results}

Figure 1 shows the mean $(\mathrm{N}=24)$ beat-to-beat change in HR on Trial Block 1 for each intensity-duration condition (points on the curves are the difference between the prestimulus HR measure and 20 successive interbeat intervals following stimulus onset). There was a brief decrease in the first two beats following onset of the $40 \mathrm{~dB}$ tone which was not apparent for the $85 \mathrm{~dB}$ tone. Statistical analysis of these initial beats, however, revealed no significant differences between the two intensity groups. In general, the HR change following the $40 \mathrm{~dB}$ tone did not appear to differ in form from that following the $85 \mathrm{~dB}$ tone. Figure 1 also shows that for the first 5-7 beats there was little difference as a function of stimulus duration; after this a marked difference appeared. For the $15 \mathrm{sec}$ tone, a decrease in HR occurred which fell below the prestimulus level at about the sixth poststimulus beat and continued for a period of $10-12$ beats. During the same period the HR following the $1 \mathrm{sec}$ tone remained largely above the prestimulus level. Thus, the HR change on initial presentations of the long tone was

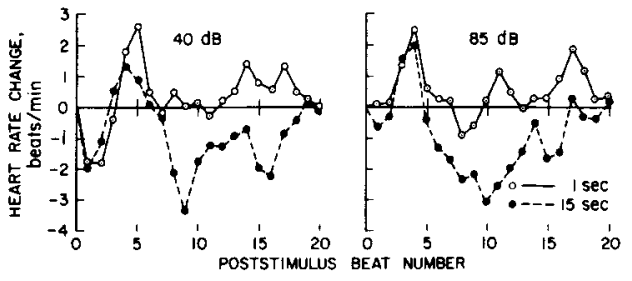

Fig. 1. Mean heart rate change on Trial Block 1 for each intensityduration condition. 


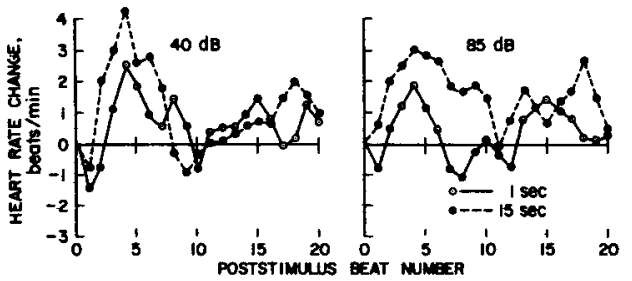

Fig. 2. Mean heart rate change on Trial Block 3 for each intensityduration condition.

characterized by a prolonged phase of deceleration while that to the short tone was predominantly one of acceleration.

The HR change observed on the remaining trial blocks is illustrated in Figs. 2 and 3. There was no apparent change or decrement in the response to the $1 \mathrm{sec}$ tone. For the $15 \mathrm{sec}$ tone the deceleration phase quickly habituated. By Trial Block 3, the response to this longer tone had become an acceleration similar to the $1 \mathrm{sec}$ tone. Then, with further repetition the response continued to be an acceleration of about the same form and magnitude.

Statistical analysis of the HR response (all trial blocks) supported these observations. There was a significant effect of duration ( $F=4.6, p<.05)$ but not of intensity, and a significant trials by duration interaction $(\mathrm{F}=2.2, \mathrm{p}<.05)$. These differences reflected the individual HR responses where on Trial Block 1 71\% were decreases (i.e., decelerations) following the long tone and $65 \%$ were increases (i.e., accelerations) following the short tone. By Trial Block 3 this had changed so that overall $67 \%$ of the individual responses were increases. Analysis of prestimulus $\mathrm{HR}$ and respiration rate revealed no significant differences for any of these measures as a function of duration, intensity, trials, or the interaction of these factors. Discussion

The HR response following tones of 40 and $85 \mathrm{~dB}$ did not support Graham \& Clifton's (1966) suggestion that a differential response would be found to initial presentations of weak and more intense auditory stimuli. Rather, stimulus duration proved to be more important in determining the form of the adult HR response. Stimulus duration may be involved in differences reported in the literature concerning the response to auditory stimuli. Thus, studies using stimulus of 5 and $10 \mathrm{sec}$ duration (Lang \& Hnatiow, 1962; McDonald et al, 1964) report a diphasic response. The published data are similar to that found here for initial presentations of the $15 \mathrm{sec}$ tone. In contrast, Uno \& Grings (1965) for a 2 sec stimulus reported a monophasic response more nearly like the acceleration to the 1 sec tone. Possibly, acceleration is

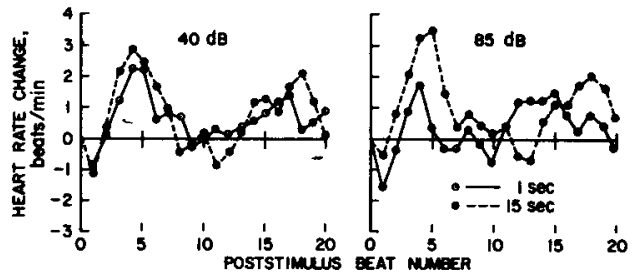

Fig. 3. Mean heart rate change on Trial Block 8 for each intensity. duration condition.

linked to onset and deceleration to prolongation of the stimulus.

Rapid habituation of the deceleration phase indicates this aspect of the response may be considered a component of orienting, since a distinguishing characteristic of the orienting response is that it diminishes rapidly when a stimulus is repeated (Sokolov, 1963). For the same reason, the persistence of acceleration makes it unlikely that this response is a component of orientation. The fact that acceleration occurred to both 40 and $85 \mathrm{~dB}$ tones indicates it cannot be considered a defensive reflex, because this response is thought to occur only to relatively intense stimuli (Sokolov, 1963). The acceleration could be a startle response, not dependent on peak stimulus intensity, but dependent upon the intensity reached within the first few milliseconds of onset (Graham \& Clifton, 1966). This might be the case for the present study since there was no control over rise time of the tones. An alternative view (Soltysik et al, 1961) is that acceleration represents an adaptive type of response, specific to auditory stimuli. This explanation would be consistent with reports (Davis et al, 1955) that non-auditory stimuli evoke only a response of HR deceleration.

\section{References}

DAVIS, R. C., BUCHWALD, A. M., \& FRANKMAN, R. W. Autonomic and muscular responses and their relation to simple stimuli. Psychol Monogr., 1955, 69, No. 20, Whole No. 405.

GRAHAM, F. K., \& CLIFTON, R. K. Heart-rate change as a component of the orienting response. Psychol Bull, 1966, 65, 305-320.

LANG, P. J., \& HNATIOW, M. Stimulus repetition and the heart rate response. J. comp. physiol. Psychol, 1962, 55, 781-785.

MCDONALD, D. G., JOHNSON, L. C., \& HORD, D. J. Habituation of the orienting response in alert and drowsy subjects. Psychophysiol, $1964,1,163-173$.

SOKOLOV, E. N. Higher nervous function: the orienting reflex. Annu. Rev. Physiol, 1963, 25, 545-580.

SOLTYSIK, S., JAWORSKA, K., KOWALSKA, M., \& RADOM S. Cardiac responses to simple acoustic stimuli in dogs. Acta Biol Exp., 1961, 236-252.

UNO, T., \& GRINGS, W. W. Autonomic components of orienting behavior. Psychophysiol, 1965, 1, 311-321.

WILSON, R. S. Autonomic changes produced by noxious and innocuous stimulation. J. comp. physiol. Psychol, 1964, 58, 290-295. 